\title{
Developing Disease State Management in the United Kingdom: An Obviously American Conjecture Finds Export Opportunites Abroad
}

Swu-Jane Lin

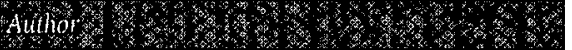

SWU-JANE LIN, B.S. PHARM, M.S. Public Health, is a Ph.D. student at the University of Illinois at Chicago, College of Pharmacy, Department of Pharmacy Administration, Chicago, IL.

ACKNOWLEDGMENT: The author wishes to thank J. Warren Salmon, Ph.D., Professor, Sanjay K. Gandhi, Ph.D. candidate, and Elizabeth Krause, Pharm.D. at the College of Pharmacy, University of Illinois at Chicago, for assistance in developing this manuscript.

Copyright (C) 1998, Academy of Managed Care Pharmacy, Inc. All right reserved.
$\mathrm{T}$ he term "disease state management" (DSM) first received general recognition at the Pharmaceutical Manufacturers Association meeting in April 1993 as part of a study by the Boston Consulting Group on the value of pharmaceuticals in the health care system.' Since that time, managed care has widely embraced DSM. A recent U.S. survey shows that $68.1 \%$ of health maintenance organizations (HMOs) have DSM programs in place for the five most frequently targeted diseases: asthma, diabetes, congestive heart failure, gastrointestinal disorders, and depression. ${ }^{2}$ Yet there is no universally accepted definition for DSM. So far, attempts to define DSM remain abstract rather than operational, which opens them to wide interpretation:

A "[DSM is] a comprehensive integrated system for managing patients by using best practices, clinical practice improvement information technology, and other resources and tools to reduce overall cost and improve measurable outcomes in the quality of care" 3

$\Delta$ "[DSM is] a comprehensive integrated approach to care and reimbursement based fundamentally on the natural course of a disease, with treatment designed to address the illness with maximum effectiveness and efficiency."

A "[DSM] targets populations with a specific condition and involves the implementation of coordinated, comprehensive interventions that will improve the clinical, humanistic, and economic outcomes associated with the management of that condition."

These definitions are somewhat unrealistic because: 1) no strong evidence exists to support "best practices" for many diseases; 2) the information technologies needed for outcome evaluation and clinical practice improvement still are under development; and 3) a reimbursement scheme based on the natural course of a disease is difficult to foresee.

Because DSM is population based, prevention focused, information intensive, and teamwork oriented, it appeals to most health care professionals. Yet there is no consensus on exactly what DSM should be, perhaps due to professional skepticism toward DSM's primary advocates: pharmaceutical manufacturers and managed care executives. Due to the lack of a clear operational definition of DSM that can be applied structurally across multiple disease states, components of health care interventions are sometimes mistaken for, or promoted as, DSM.+ Thus, it is. not-surprising that so-called DSM programs can range from very low-tech interventions, such as the distribution of patient education pamphlets or the revision of patient education brochures, to the development and implementation of highly sophisticated treatment protocols.

Besides the lack of consensus on the content of a DSM program, few research studies exist to prove DSM's effectiveness in increasing the value of health care. After more than four years of clinical practice on DSM, there remains no strong evidence in the scientific literature to demonstrate the effectiveness and efficiency of these programs. ${ }^{6}$ It is too early to judge the merit of many programs, but decisions to allocate health care resources must be based on evidence.

Perhaps the most controversial aspect of DSM is the motive of pharmaceutical companies or their affiliates in 
developing these programs. Pharmaceutical companies first developed DSM as a strategy to adapt to the rapid growth of managed care and its increasing pressure to negotiate drug price discounts, and to minimize the loss of market share to generic competitors. By providing evidence to support that embedding drugs with value in DSM programs actually can eliminate more expensive interventions in the later stages of the disease process, some pharmaceutical companies may be seeking a way out for their beleaguered products.

\section{EXPORTING A SOCIAL TECHNOLOGY}

Despite this uncertainty and the lack of concrete evidence on long-term effectiveness, this new tool for allocating health care resources already has found its way across the Atlantic Ocean to the National Health Service (NHS) of Great Britain. The NHS drug budget amounts to only $10 \%$ of overall government health spending, but it always has been an easy target for cost containment. By introducing DSM programs, pharmaceutical companies are not only aiming to secure that $10 \%$ but also are targeting nonpharmaceutical health care, which comprises $90 \%$ of the NHS expenditure. The goal of DSM, as claimed by adherents, is to reduce the total cost of managing a complex disease and improve the quality of care at the same time, when the component costs of drugs in such a scheme may be the same or greater than before. Cost containment programs will focus on the total cost, rather than on component costs, of managing a disease. DSM programs also give pharmaceutical companies the opportunity to position themselves as private health service providers and not merely producers of drugs.

The NHS is keen on the development of DSM programs in the United Kingdom. Burns pointed out that the NHS has become fertile ground for disease state management but expressed concern about the commercial force driving those programs.' Officers of the NHS also are closely monitoring the development of DSM. In December 1994, NHS Executive, the branch of NHS responsible for translating policy into practice and monitoring NHS performance, declared its opposition to a deal between NHS purchasers and providers and commercial companies that offer disease management packages. The Executive voiced concern that such packages could inhibit competition, violate patient confidentiality, and adversely affect a physician's choice of pharmaceuticals for his or her patients.

But in 1996 that negative attitude seemed to change. A discussion paper of the NHS Executive indicated that the government neither encouraged nor discouraged ventures between NHS and private sector companies. ${ }^{8}$ In mid-1997, with the collaboration of Calderdale and Kirlees Health Authority, a group of 23 pharmaceutical companies in the United Kingdom started a number of education programs and disease-management projects. These programs might well become a pilot for DSM programs. ${ }^{9}$

An intended program can best demonstrate an impact when it targets an area with lots of room for improvement. Does the NHS render itself a suitable target in need of another performanceenhancing tool? In 1995, Britons spent $\$ 1,300$ per person on health care, while U.S. citizens spent almost three times as much, and the health indicators of these two countries are not significantly different. ${ }^{10}$ Grêat Britain's total annual health expenditure is $£ 43$ billion [about $\$ 67.8$ billion, or $6.3 \%$ of Gross Domestic Product (GDP), 1991]..1 The NHS delivers free health services to all citizens. In contrast, in the United States, with more than $14 \%$ of GDP (1993) spent on health services, a sizable proportion of the population (4345 million, or $17 \%$ ) has no medical insurance, ${ }^{12}$ with an equal number of Americans underinsured.

While a variety of managed care tools exist to control pharmaceutical expenditures in the United States, the NHS uses both macro- and microapproaches to contain costs. On the macro level, a pharmaceutical price regulation scheme has been in place in the
UK since 1969, although what it actually regulates is profit, not price. The scheme allows pharmaceutical companies to keep a profit of $17 \%$ to $21 \%$ on their sales to the NHS; it also imposes regulations on price increases, advertising expenditures, and research and development (R\&D) expenditures permitted as a cost of supplying drugs to the NHS. ${ }^{13}$ However, owing to the lack of impact analysis, the effectiveness of the profit control scheme still is unclear. ${ }^{14}$ According to data from Scripps Pharmaceutical Company League Tables, drug companies worldwide made an average $11.3 \%$ margin in 1994; when the two companies that made over $90 \%$ return are excluded, the average margin for drug companies worldwide was $9.5 \% .^{15}$ Thus, a $17 \%$ to $21 \%$ profit target in the Price Regulation Scheme certainly raises concern.

On the individual practitioner level, several initiatives are aimed at changing prescribing behavior. These include feedback from a prescribing analysis and cost (PACT), the implementation of indicative prescribing budgets, and general practice fundholding. " Fundholding general practitioners have to be responsible for their own budget to purchase care for patients. The budget includes staff, prescribing, some investigations, and referrals to secondary care providers. The effectiveness of these micro-level controls is still unknown due to the lack of concrete evidence from randomized studies. The limited studies available seem to indicate the costs of prescribing were contained and the proportion of generic dispensing was increased after the fundholding. However, whether the effect can be sustained in the long run still is uncertain..$^{12.14}$

With the mixed strategies of macroand micro-control, Britons scored an average annual pharmaceutical expenditure per person (prescribed and nonprescribed, in 1990) of $£ 64$ (\$96); Americans spend $(\$ 165) £ 110$. In 1989 , Britons purchased an average of eight prescription items per person; Americans bought 17 per person per year. Generics comprised $43 \%$ of substances prescribed 
- Continued from page 276

in Britain (1992) and about 40\% in the United States. The United Kingdom has a lower rate of medication utilization overall than the United States.

Since the NHS always has been a highly regulated "managed care" organization with lower costs (and sometimes criticized for underproviding certain services), it is questionable that such a system may benefit from experience derived from a high-cost, lightly regulated, and overprovided environment. ${ }^{15}$ What follows is a description of the changing environment of the British NHS and the potential to transplant an allocation tool, DSM, originating in American private managed care to a predominantly public and highly planned health care system.

\section{A BRIEF INTRODUCTION TO DSM}

DSM is an application of outcomes management, a population-based approach (instead of individual patientbased) to identify groups at risk, intervene with specific programs of care, and measure clinical, economical, and humanistic outcomes when possible and appropriate in the groups. Most DSM programs focus on chronic conditions such as asthma, diabetes, and gastric ulcers. Programs on arthritis, heart diseases, and depression also are under development. In the United States, pharmaceutical companies playing zealously in this field include PharmaciaUpjohn, which created a separate unit -Greenstone Healthcare Solution-for its DSM activities; Eli Lilly, which has established Integrated Data Management as a separate division to develop DSM programs; Merck/Medco, which plans to incorporate financial incentives into its pharmacy benefits (PBM) management services to encourage patients to enter DSM programs; and Zeneca Pharmaceuticals, which has acquired a 50\% interest in Salick, a cancer center operator, to expand its provider capabilities and cancer database for a DSM program. ${ }^{16}$

Comparable to the DSM programs initiated by pharmaceutical companies are in-house DSM programs initiated by health plans themselves. Because DSM programs share some fundamental concepts of quality improvement (such as continuously measuring the pivotal components and outcomes of a health care intervention and modifying behavior of patients and providers based on measured data with general quality improvement programs), more and more health plans claim to have assimilated the concept of DSM programs into their quality assessment and improvement efforts. In a 1996 report, two-thirds of HMOs indicated that they intended to develop DSM programs independently, without involving drug manufacturers. ${ }^{5}$

In the U.K. , the privately provided DSM programs have yet to be put in place, but the recently launched collaborative projects by 23 pharmaceutical companies and NHS Health Authorities might be ground-breaking progress for developing DSM programs in this highly planned health care system. ${ }^{10}$

\section{THE INVITING ENVIRONMENT OF THE BRITISH NHS}

In the half-century history of the National Health Service, no major change has had the magnitude and influence of the 1989 reform blueprinted by the Thatcher government. The three major mechanisms introduced were competition, purchaser/ provider split, and general practice fundholding. An internal market was created to separate the financing of health care from its provision; hospitals were set up as self-governing trusts with budgetary autonomy that are allowed to sell services to various purchasers from the private and public sectors; and general practitioners (GPs) now are encouraged to form fundholders to assume the dual roles of providers and purchasers of health care services on behalf of their patients.

GP fundholding may look like the capitation payment scheme commonly used to pay primary care physicians in the U.S., but the incentives designed into the two methods are quite different. Under U.S. capitation, savings from the practice are generally at the disposal of physicians or the health care organizations. In the GP fundholding design, however, there are strict regulations on how the savings, or profits, can be used. In a sense, the regulations make fundholding GPs look like not-for-profit organizations. In addition, a stop-loss mechanism is built into fundholding to prevent financial catastrophe.

The emphasis on primary care-led health care and the gradually increased scope of fundholding, both in population and services, have placed the GPs at the forefront of a holistic health care system. However, the development also puts GP fundholders under increasing financial risk. Similarly, the other primary purchasers of NHS services-the District Health Authorities (DHAs) - are facing the same pressure. A DHA is responsible for purchasing cost-effective health care for the population in its geographic surrounding communit and is required to absorb the extra costs for GP fundholders when any of their patients consume more than $\mathfrak{£ 5 , 0 0 0}$ of health care in one year.

The instilling of market forces into this planned health care system has placed greater demands for responsibility and responsiveness upon both health care providers and purchasers. Competition among purchasers and providers-though far from intense by American standards--has created increasing performance pressure. Under such circumstances, managed care tools, such as DSM programs, that theoretically provide health care with better value should be welcomed.

\section{THE PRIMARY CARE-LED NHS}

Primary care comprises more than $80 \%$ of the services delivered in Britain. The nature of primary care in the NHS is continuous, comprehensive, and generalist-centered, while secondary care is episodic and specialist-centered. The strength of the NHS primary care system lies in its ability to provide both easy access and gatekeeping admission to more sophisticated and expensive 
components of medical care. Relationships between generalists and specialists are formally structured for efficiency and effectiveness.

After the 1989 reform, group practice GPs were given the budget and capacity to oversee home health services, rehabilitative services and physical therapy, drugs, specialty referrals and testing, several kinds of elective specialty procedures, and prevention care. ${ }^{17}$ At the same time, solo practice has shrunk GPs increasingly work in small groups in collaboration with nurses, social workers, and other health care personnel. Because GPs and their patients tend to establish long-term relationships, GPs are in a good position to provide community-needed health care, to seek out at-risk groups, to promote health, and to prevent diseases.

From the beginning, the health center was one of the pillars of the NHS. About $30 \%$ of GPs now rent the health centers provided by local authorities. The health center was designed to bring primary care, disease prevention, and health promotion to people where they live and work. ${ }^{12}$ Relatively few HMOs. in the United States have achieved this.

The NHS also designed a mechanism to encourage preventive care. The 1990 GP contract provides financial incentives for targeted rates of immunization and health surveillance for children, pap smears for women, and medical check-ups for all new patients and those older than 75 . In 1993, $95 \%$ of GPs achieved the targets.

Because the NHS provides group practices with $70 \%$ salary reimbursements for employed staff, primary care teams have developed. Most practices also have NHS-employed personnel such as district nurses, psychologists, dietitians, clerks, health visitors, and community midwives assigned to work with them. On the whole, a group of five GPs is likely to work in a team of 36 or more individuals. ${ }^{12}$

All these efforts illustrate the NHS determination to establish a primary care-led health care system centered on prevention and teamwork.

\section{CAPITATED FUNDING}

After the 1989 reform, two organizations became responsible for purchasing health care services for the public: the District Health Authorities (DHAs) and the GP fundholders. DHAs are responsible for assessing health care needs of their populations and for purchasing a range of services covering hospitals, mental health services, and community care. GP fundholders purchase most routine surgery, outpatient, and specialist nursing care for their patients.

An average DHA covers about half a million people. DHAs receive funding according to a weighted capitation from the central government. In addition to purchasing services for the population in its district, the DHA also is responsible for the extra cost of any patient of GP fundholders that consumes more than $£ 5,000$ in one year, and the cost of emergency admissions initiated by GP fundholders. The GP fundholders are paid largely on a capitated basis. ${ }^{18}$ Even though they can shift some risk to DHA and providers, GPs, because of their smaller patient populations and budgets, still may have problems with effective financial control and might therefore be induced to,select healthier patients. Already some GPs have shown a preference for patients with private insurance. ${ }^{19}$

The scope of health care covered by GP fundholding might be increased in the near future. In April 1995, there were 53 total purchasing pilot projects in England and Scotland; another 35 projects began in April 1996. The pilots were to start purchasing in April 1996 and run until April. 1998. The total purchasing program may empower GPs to purchase all hospital and community health services for their patients. ${ }^{20}$

Increasing financial constraints and risk may force both DHAs and GP fundholders to ration resources. The DSM programs, with their claimed effectiveness and efficiency, could aid in rationing resources without sacrificing the quality of care because they function as resource-allocation tools. In the programs, high-risk patients are identified and mechanisms such as preventive care and patient education are used to redirect the utilization pattern of this subgroup from high-cost tertiary treatment to more cost-effective preventive and primary care. If the DSM programs can demonstrate their value, health resources may be more effectively allocated and overall quality of care may be improved.

\section{RATIONING BY EVIDENCE- BASED MEDICINE PRACTICE}

"Rationing" may sound like a negative word to the American public. However, virtually every provider working under budget - whether a capitated physician in the United States or a fundholding general practitioner in the British NHS-rations health resources routinely. Rationing may be explicitly carried out according to government regulations (e.g., kidney dialysis in the United Kingdom) or, more frequently, implicitly rendered by personal values or aggregate experience on medical interventions (e.g., HMO restrictive drug formularies in the United States). The involvement of personal judgment in medical practice inevitably raises the problem of inconsistency and inadequate treatment of some diseases. The use of coronary artery bypass graft surgery and coronary angioplasty among health districts in the United Kingdom varied so widely as to raise the suspicion that too few might be performed in many areas of the country. The average cost in 1986-87 for treating acute hospital inpatients varied by as much as $50 \%$ in different areas, even after adjusting for the complexity and mix of cases. In the same way, waiting times, referral rates, and prescribing habits varied sharply among general practitioners. ${ }^{21}$

These facts suggest that an experience-based or informally consensusbased rationing method is no longer justifiable. Evidence-based medical practice in the United Kingdom has arisen to ensure cost-effective use of health 
care resources. If not for the fact that the majority of health care interventions have not been formally evaluated for their effectiveness, and their likely impact upon health status is largely unknown, the rationing scheme might easily follow evidence-based medicine implementation. According to a Canadian study, only $20 \%$ of health care activities have been formally evaluated. ${ }^{22}$

To overcome this inherent weakness, the NHS has placed an increasing emphasis on research-based knowledge. The NHS has begun several initiatives, including the establishment of the UK Cochrane Center at Oxford and the NHS Center for Reviews and Dissemination at York, as well as the provision of information to health authorities to enable them to concentrate resources on services of proven clinical effectiveness. ${ }^{23}$ These efforts are designed to encourage the clinicians and the purchasers to draw on evidence in deciding which services to provide or to purchase. The NHS executives also believe in the use of contracting to promote effective medical care. Purchasing based on guidelines or protocols, rather than on activity, was once advocated..$^{24} \mathrm{~A}$ study of quality contracting found that nearly one-half of the DHAs surveyed adhered to some quality protocols. ${ }^{23}$ By encouraging evidence-based medicine in general and guidelines in particular, the NHS hopes to achieve a more appropriate allocation of limited resources. Increasing efforts to develop disease state management programs in the independent sector have the same stated purpose.

An efficient information system is necessary to provide the infrastructure for collecting data and to establish the evidence base. The information system has to be able to assimilate the clinical and administrative data, to analyze the integrated database, and to generate information to support decision making. The British Department of Health has in recent years invested heavily in upgrading computer systems, which could become an important foundation for the development of DSM programs. However, whether the private sector should have access to the publicly funded information system to collect health care information for its proprietary programs is under debate. Correspondingly, whether the private sector, such as the DSM program providers, would be willing to share their database on disease management and the effectiveness of competing pharmaceuticals also is highly doubtful. These questions will be resolved only when the industry can prove that the public database will be used for achieving public good, instead of company selfinterest, and the public health information system benefits in its analytical usefulness from the feedback of proprietary diseaśe management information.

\section{THE GROWING PRIVATE HEALTH SECTOR}

In contrast to the United States, the private health care sector in the United Kingdom exists merely as a supplement to the NHS. Private expenditure on health care comprises about $15 \%$ of total health expenditure in the United Kingdom and covers mainly elective surgeries such as the "three h's"-hips, hernias, and hemorrhoids. ${ }^{25}$

The primary purchasers of private health care are patients with private insurance and cash. Private insurance covers $13 \%$ of the total population and is provided principally as an employment benefit to selected white-collar workers and their families. The main reason people become private patients is to avoid the NHS's notoriously long waiting lists for surgery ${ }^{30}$ Lee has characterized this as "the private patient pays to avoid waiting; the NHS patient waits to avoid paying." ${ }^{26}$

The other two categories of private health care purchasers are DHAs and fundholding GPs. The DHAs are allocated a certain amount of budget, according to the size and characteristics of their resident population, to purchase health services from NHS trusts and private and voluntary suppliers. The fundholding GPs also have the right to buy a defined range of hospital treatments for patients from providers either inside or outside the NHS. ${ }^{27}$

The supply side of private health care ranges from hospitals still directly managed by health authorities to selfgoverning NHS trusts and entirely private suppliers of services. The privately owned suppliers include, among others, hospitals built by American health care companies and British private insurance companies. The largest British private insurer, BUPA, now owns 29 hospitals. There are 224 acute private hospitals in Britain - one private hospital within a mile of every major district general hospital. ${ }^{30}$ In addition, BUPA has announced that it will provide some primary care services ${ }^{28}$ Clearly, the private insurers gradually have become both important purchasers and providers of the health care services.

The expansion of the private health care sector has brought pressure upon almost every player in the health care system. The providers that traditionally depended upon NHS purchasers to support their business, such as the selfgoverned trusts, now face competition from private providers. And the primary private purchasers, the private insurers, not only have to compete with each other for survival-because the patients always have the NHS as their alternative-but also have to demonstrate the value of the insurance by providing quality health care with an acceptable premium.

Increasing competition has impelled the private health care providers and purchasers to resort to managed care measures. Although the prevailing opinion is that the wholesale adoption of an American managed care system is impossible in Britain, some private insurers believe there are good ideas in the U.S. system that, properly translated, can benefit their business. ${ }^{29}$ For example, clinical guidelines were developed and used in high-cost, high-volume elective surgery, which constitutes the bulk of private medical insurers' business. ${ }^{19}$

Managed care is in its infancy in the private sector of the British health 
care system. Whether it will result in a cooperative relationship between clinician and manager, or another bureaucratic measure for containing cost that leaves clinicians and patients unsatisfied, is yet to be seen. It seems certain that the experience obtained in the private sector can be an important guide to the NHS for further policy making.

\section{COUNTERFORCES TO THE DEVELOPMENT OF DSM}

\section{Small-Scale GP Fundholders}

GP fundholders are essentially small-scale HMOs. Initially each fundholding was designed to encompass 11,000 patients or more, subsequently reduced to 9,000 patients, then to 7,000 , and recently to $5,000 \cdot .^{15}$ DSM is a population-based management tool; if the population base is too small, it may be difficult to detect significant or meaningful benefit, or the effect may be too minimal to justify the investment. Other inherent disadvantages include the high transaction cost and the relative powerlessness of GP fundholders when confronting the major providers. ${ }^{18}$

A solution to these disadvantages lies in the formation of "multifunds," which were created to assist with the additional financial management duties that arise when a GP becomes fundholder. By pooling individual fundholders' management allowances, a multifund enables the establishment of an efficient management team which cannot be afforded by any single practice. ${ }^{30}$ Such multifunds can comprise more than $100 \mathrm{GP}$ fundholders and become powerful purchasers of quality health care.

The large scale of multifunds also makes them ideal for outcomes research. Such research can help fundholders purchase effective interventions, negotiate with government for more adequate funding, and justify ethical rationing under limited budgets. ${ }^{35}$ If GP fundholding can survive the Labour government's health policy and keep its momentum, these quasi-HMO multifunds could be an appropriate setting in which to test the purchasing of DSM programs.

\section{Shifting Political Power Implications for the NHS}

In May 1997, Britons decided they had had enough of the Tories after 19 years in power. Ten Downing Street is now back in the hands of the founder of the NHS, the Labour Party. The market principles imposed in the 1989 reform were regarded by many as a road map to privatization for the NHS, and that became one of the central charges of Labour Party against the Tories. The Labour Party has pledged to abandon GP fundholding and, with it, the internal market. Before the election, Labour's plan was to replace individual fundholding with a system of local commissioning in which 10 or 20 practices negotiate a common budget for hospital treatment of their patients. Single practice fundholding would be frozen and totally replaced within three years. ${ }^{31}$

In mid-September of 1997 the Labour government issued its official guidance to dilute the internal market. Purchasers and providers remain split, but their interactions will now center on cooperation rather than competition. Financial transparency for health authorities, GPs, and the NHS trusts is advised in the guidance, and the health authorities are required to allocate increasing amounts of budget on longer term of contracts covering at least three years. $^{32}$

The guidance is clearly a beginning to the dismantling of the internal market created by the last Conservative government. However, because the Conservative government never succeeded in bringing about genuine competition, and perhaps never wished to do so, the real impact is yet to be determined. ${ }^{33}$ The power general practitioners obtained from the 1989 reform will likely remain, whether the GPs are practicing under the banner of fundholding or local commissioning. GPs will still be in charge of most resources delegated to the majority of the population.

Conservative government health policy was always branded by opponents as an attempt to privatizé the
NHS. The Labour government is unlikely to be enthusiastic about input from the private health sector. With fundamental mistrust, unresolvable ideological conflicts, and the formally abandoned market forces, the new government has painted a rather gloomy picture for the private health sector. Similarly, it might be more difficult than before for pharmaceutical companies or DSM providers to enter into the mainstream of the British health care system. However, inasmuch as Prime Minister Tony Blair mirrors President Bill Clinton, his compromised policies may be indistinguishable from the opposition party.

\section{"Carve-out" Control Creates Problems}

The central idea of DSM is to better manage the $20 \%$ of patients who consume $80 \%$ of resources. In order to concentrate on these well-defined populations and to obtain maximum efficiency, targeted conditions are carved out for rigorous control by the DSM team. Provider groups, PBMs, and pharmaceutical manufacturers provide the pharmaceutical carve-outs in the United States. DSM programs also are provided to health plans as a carve-out. The diseases most often targeted for carve-out are diabetes, asthma, congestive heart failure, and cancer.

The carve-out approach apparently creates at least two problems. First, the patients will likely have more than one disease; thus the program provides only a partial solution. And second, the chosen disease might be the more profitable one to treat, encouraging a "cherry-picking" effect that may have negative impact on the case-mix of the patient population. To potential purchasers, such as the GP fundholders, the first problem will cause difficulties in contracting with DSM program providers. Usually the concomitant diseases are interwoven, which makes the beginning and the end of responsibility obscure. The cherry-picking effect, in which companies target only profitable conditions or diseases, might leave the 
NHS a residual to cover more expensive conditions. For example, a company might cover endoscopies for patients with dyspepsia, which would make the per-case cost of a hospitalmaintained gastroscopy service dealing with gastrointestinal hemorrhages more expensive. ${ }^{28}$ Traditional private insurance coverage for the "three h's" surgery is another obvious practice of carveout, while the expensive long-term illnesses are left to the NHS. For example, there is not one private hemophilia patient in Britain. These drawbacks have created concerns among some researchers and officials of NHS.

\section{CONCLUSION}

Although the pharmaceutical budget amounts to only $10 \%$ of overall NHS spending, because of its transparency it is seen as an easy target. DSM programs give the pharmaceutical industry a chance to present drugs in the context of overall clinical management when attempting to justify or extend spending on drugs that are proven cost effective downstream in the care continuum. It also paves the way for pharmaceutical companies and PBMs to become health care providers, not just product providers.

The private DSM providers claim the ability to provide a continuum of disease management for certain diseases and certain parts of the population. The efficient allocation of health care resources in DSM is based on a simple management rationale (the 20/80 rule) to manage the small fraction of patients that consume the majority of health care. However, for the NHS, the allocation of resources is a compromise of politics and social equity, as well as efficiency and effectiveness. Private providers have to overcome the differences in ideology, incentives, and bureaucracy among their potential purchasers-the health authorities, GP fundholders, and the private insurers. Without doubt, the negotiating process will be longer and far more complicated than in the United States. In the prevailing American managed care environment, both the purchasers and the providers of DSM programs know very clearly about each other's agendas.

In the design of the NHS, the emphases on primary care, community health, and the gate-keeping role of the GP have resulted in a relatively cheap and satisfactory health care system, in terms of health indicators, that many countries can hardly hope to achieve. In a highly managed system such as the NHS, how can a private DSM provider find a niche? Who will want to pay for management overhead, when they can have all the management they may need for free?

The answers will depend on the result of the collaboration between the private sector and the NHS, and whether their weaknesses and strengths can complement each other in the effort. The DSM providers with experience in the American market might provide an effective approach to managing diseases, and their strength in performing outcomes analysis may instill new vitality into the 50-year-old NHS. But more important, the collaboration may provide an opportunity to examine how private providers can be incorporated effectively and ethically into a publicly funded health care system. This will shed light on the future policy direction of the NHS.

For American DSM providers, the collaboration gives a vital opportunity to test the programs in a well-structured system-a system that has all the components for holistic care and outcome research already in place. From the community health care team to systemic referral for specialty care, from a highly computerized GP practice to a continuing endeavor in evidence-based medicine and outcomes research, the NHS has provided a context for DSM providers to demonstrate their credibility In this context, DSM providers can carry out their long-awaited, welldesigned, and controlled randomized studies. The social experiment will be able to prove that their preaching and practicing of DSM are based on con- crete evidence, and not incomplete and flawed information, nor pure faith.

\section{Relerences}

1. Broshy E, Matheson D, Hansen M. Want to curb health costs? Manage the disease, not each cost component. Med Marketing Media 1993; 28(9): 76 .

2. Navarro RP, ed. Pharmacy benefit report trends $\&$ forecasts. Summit, NJ: Novartis; 1997: 2.

3. Bernard S. Disease management:

Pharmaceutical industry perspective. Pharm Exec 1995; March: 48-50.

4. Zitter M. Disease management: A new approach to health care. Med Interface 1995; 7(August): 70-72, 75-76.

5. Coons SJ, Disease management: Definitions and exploration of issues, Clin Ther 1996; 18: 1321-26.

6. Curtiss FR. Lessons learned from projects in disease management in ambulatory care. Am J Health-Syst Pharm 1997; 54: 2217-29.

7. NHS Executive. Commercial approaches for the NHS regarding disease management packages. Leeds: NHSE, 1994.

8. Hunter DJ, Fairfield G. Managed care: disease management. BMJ 1997; 315: 50-53.

,9. UK pilot disease management scheme. Scrip World Pharmaceutical News. 1997; 2237:3

10. Britain: an unhealthy silence. The Economist 1997; March 15: 57-58.

11. Compendium of health statistics. London, England: Office of Health Economics; 1995. 12. Fry J, Light D, Rodnick J, Orton P. Reviving primary care: a US-UK comparison. Oxford: Radcliffe, 1995

13. Bloor J, Maynard A, Freemanule N. Lessons from international experience in controlling pharmaceutical expenditure [1l: regulating industry. BMJ 1996; 313: 33-35

14. Earl-Slater A. Regulating the price of the UK's drugs: second thoughts after the governmentis first report. BMJ. 1997; 314: 365-68.

15. Scrip's 1995 Pharmaceutical Company League Tables. Richmond, Surrey: PJB Publications, 1995.

16. Bloor K, Freemantle N. Lessons from international experience in controlling pharmaceutical expenditure 11 : influencing doctors. BMJ 1996; 312: $1525-27$

17. Bradlow J, Coulter A. Effect of fundholding and indicative prescribing schemes on general practitionersí prescribing cosis. BMJ 1993; 307: 1186-89.

18. Maxwell M, Heaney D, Howie J, Nobel S. General Practice lundholding: observations on prescribing patterns and cost using the defined daily dose method. BMJ 1.993; 307: 1190-94. 19. Stewart BS, Surender R, Bradlow J, Coulter A, Doll H. General practice fundholding: effects on prescribing habits three years on. BMJ 1995; 311 $1543-47$.

20. Lawrence $M$, Williams T. Managed care and disease management in the NHS: What will be the role of the pharmaceutical industry? BMJ. $1996 ; 313: 125-26$.

Continued on page 287 
In the placebo-controlled studies, when SGOT (AST) and SGPT (ALT) were evaluated, $0.4 \%$ (1/250) placebo patients and $0.3 \%$ (2/795) lansoprazole patients had enzyme elevations greater than three times the upper linit of nomal range at the final treatritent visit. None of these patients reported jandice at any time during the study.

Amoxicillin:

The following adverse reactions from the labeling for amoxicillin are provided tor information.

As with other penicil lins, it may be expected that untoward reactions will be escentially limited to sersitivity phenomena. They are more likely to occur in individuals who have proviously demanstrated hypersensitivity to penicillins and in those with a history of allergy asthma, hay tever, or urticaria.

The following adverse reactions have been reported as associated with the use of penicilin Gastromitestina - Glossits, stomatitis, black "hairy" tongue, nausea, yomiting, and dianhe (These reactions are usually associated with oral dosage forms.)

Hypersensitivity Reactions - Skin rashes and urticaria have been reported trequenty. A few cases of extoliative dermatitis and erythema multiforme have been reported. Anaphylaxis is the most serious reacion experienced and has usually been associated with the parentera dosa form. Urticaria, other skin rashes, and serum sickness-like reactions may be controlled with antihistamines and, if necessary, systemic corticosteroids. Whenever such reactions occu penicillin should be discontinued unless, in the opinion of the physician the condition being treated is life threatening and amenable only to penicillin therapy. Serious anaphylactic reactions require the immediate use of epinephrine, oxygen, and intravenous stercids.

Liver - A moderate rise in serum glutamic oxaloacetic transaminase ( $\mathrm{S} G 0 \mathrm{~T}$ ) has been noter, paricularly in infants, but the significance of this finding is unknown.

Hemic and Lymphatic Systems - Anemia, thrombocytopenia, thrombocytopenic purpura eosinophilia, leukopenia, and agranulocytosis have been reported during therapy with the penicilins. These reactions are usually reversible on discontinuation of therapy and are believed to be hypersensitivity phenomena.

Rarely, erythromycin and clarithromycin have been associated with ventricular archythmias including ventricular tachycardia and torsades de pointes in individuals with prolonged ${ }^{2} \mathrm{~T}_{\mathrm{C}}$ intervals.

Changes in Laboratory Values: Changes in laboratory values with possible clinical significance were as follows: Hepatic - elevated SGPT (ALT) <T\%, SGOT (AST) <1\%, GGT <1\%, alkaline phosphatase $<1 \%, L D H<1 \%$, total bilirubin $<1 \%$; Hematologic - decreased WBC $<1 \%$, levated prothrombin time $1 \%$; Rental- elevated BUN $4 \%$, elevated serum creatirine $<1 \%$. GGT, alkaline phosphatase, and prothrombin time are from adult studies only.

Clarithromycin:

The following adverse reactions from the labeling for clarithromycin are provided for information The majority of side effects observed in clinical trials were of a mild and trancient nature Four han $3 \%$ of adult patients without mycobacterial intections discontinuer therapy becouse of drug-related side effects.

The most frequently reported events in adults were diarmea $(3 \%)$, nausea $(3 \%)$ abnorma laste $3 \%$ ) dyspepsia (2\%) abdominal pain/discomfort (2\%) and hearlache (2\%) Most of these events were described as mild or moderate in severity. Of the reported adverse events, only $1 \%$ was described as severe
Postmarketing Experience:

Allergic reactions ranging from unticaria and mild skin enuptions to rare cases of anaphylaxis

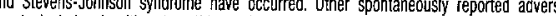
events include glossitis, stomaitis, ofal moniliasis, voniting, tongue discoloration, and dizziness. There have been reports of tooth discoloration in pabents treated with clarithromycin. Tooth discoloration is usualy reversiole with professional dental cleaning. There have been isolated reporis of heaing loss, which is usually reversible, occurring chiefly in elderly women. Reports of atterations of the sense of smell, usually in conjunction with taste perversion have Teen reported.

Tansient CNS events including anxiety, behavioral changes, confusional states, depersonalization, disorientation, hallucinations, insomnia, nightmares, psychosis, timnitus, and vertigo have been reported during postmarketing surveillance. Events usually resolve with continuation of the drug

hepatic dystunction, induding increased iver enzzymes and hepatocelluiar andior cholestatic hepatitis, with or without jaundice, has been infrequently reported with clanthromycin. This hepatic dystunction may be severe and is usually reversible. In very rare instances, hepatic tailue wint fala ollcome has been reported and generally has been associated with serious underlying diseases andír concomitant medications.

\section{OVERDOSAGE}

In case of an overdose, patients should contact a physician, poison control center, or emergency room. There is neither a pharmacologic basis nor data sugnesting an increased toxicity of the combination compared to ind vidual components.

\section{Lansoprazole:}

Oral doses up to $5000 \mathrm{mg} / \mathrm{kg}$ in rats (approximately 1300 times the $30 \mathrm{mg}$ human dose based on body surface area) arid mice (abcut 675.7 times the $30 \mathrm{mg}$ human cose based on body sufface areal did not produce deaths or any clinical signs.

Lansoprazole is not removed from the circlation by hemodialysis in one renorted case of overdose, the patient consumed $600 \mathrm{mg}$ of lansoporazole with no acverse reaction.

\section{Amoxicillin}

In case of overdosage, discontinue medication, teat symptomatically and institute supportive measures as required. Amoxicilin can be removed from circulation by hemodialysis.

PREVPAC is distributed by TAP Pharmaceuticals Inc.

PREVACID ${ }^{\oplus}$ (lansoprazole) Delayed-Release Capsules

Manufactured for

TAP Pharmaceuticals inc.

Deerfield, Illinois 60015-1595, U.S.A

by Takeda Chemical Industries, Limited.

Osaka, Japan 541

Distributed by TAP Pharmaceuticals Inc.

\section{DAPOTHECON \\ A BRISTOL-MYERS SOUIBE COMPANY}

TRIMOX (amoxicillin, USP)

Manufactured by

APOTHECON ${ }^{\circ}$

A Bristol-Myers Squibb Company

Princeton, NJ 08540, U.SA

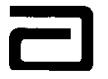

BIAXIN Filmtab (clarithromycin tablets)

Manufactured by

Abbott Laboratorie

North Chicago, IL 60064, U.S.A

(B--Registered Trademark

For more detailed information, see Full Prescribing Information or contact TAP Medical Services 1-800-478-9526.

Developing Disease State Management in the United Kingdom

\section{Continued from page 283}

21. The Intelligent Healthcare Source. Disease management shows great promise. [resource on World Wide Web]. URL//medsource.com/ pro7.html. Available from Internet. Accessed 1997 Feb 11

22. Grumbach K, Fry J. Managing primary care in the United States and in the United Kingdom N Engl J Med 1993; 328: 940-45.

23. Jost TS, Hughes D, McHale J, Griffiths L. The British health care reforms, the American health care revolution, and purchaser/provider contracts. J Health Polit Policy Law 1995; 4: 885-908. 24. Culyer AJ, Meads A. The United Kingdom: effective, efficient, equitable? J of Health Politics, policy and law 1992; 4: 665-88.

25. Mays N, Goodwin N, Bevan G, Wyke S. What is total purchasing? BMJ 1997; 315 : 652-55.
26. Freementle N. Dealing with uncertainty: Will science solve the problems of resource allocation in the U.K. NHS? Soc Sci Med 1995; 40: 1365-70 27. Canadian Coordinating Office for Technology Assessment. Guidelines for economic Evaluation of Pharmaceuticals. Otlawa: COTA, 1994 28. Ham C. Population-centered and patientfocused purchasing: The U.K. experience. Milbank Q 1996; 74: 191-214.

29. McKee M, Clarke A. Guidelines, enthusiasms uncertainty, and the limits to purchasing. BMJ 1995; 310: 101-4

30. Richmond $C$. NHS waiting lists have been a boon for private medicine in the UK. CMAJ 1996; 154: 378-81

31. Michael Lee. Private and National Health Services. London: Policy Studies Institute, 1978
32. Ranade W. A future for the NHS? Health care in the 1990s. London: Longman, 1994.

Fairfield G, Williams R. Clinical guidelines in the independent health care sector: An opportunity for the NHS to observe managed care in action. BMJ 1996; 312: 1554-55.

34. Woods D. Exportability of managed care is limited. BMJ 1997:315: 701

35. D'Souza MF. The multifund and outcome research. Int J Epidemiol 1995; 24: S113-18. 36. Warden J. Labour reveals plans to dismantle internal market. BMJ 1996; 313: 1427.

37. Warden J. The beginning of the end of the internal market. BMJ 1997;315: 624.

38. Klein R. Labouris health policy. BMJ 1995 311: $75-76$ 